\title{
Start-up with or without inoculum? Analysis of an SMBR pilot plant
}

\author{
Gaetano Di Bella ${ }^{*, 1}$, Francesca Durante ${ }^{1}$, Michele Torregrossa ${ }^{1}$, Gaspare Viviani ${ }^{1}$ \\ Dipartimento di Ingegneria Idraulica ed Applicazioni Ambientali, Università di Palermo, Viale delle Scienze, 90128 Palermo, Italy
}

\section{A R T I C L E I N F O}

\section{Article history:}

Received 20 November 2009

Received in revised form 26 April 2010

Accepted 29 April 2010

Available online 31 May 2010

\section{Keywords:}

Complete sludge retention

Floc size

Fouling resistances

Inoculum

Sludge production

Start-up

\begin{abstract}
A B S T R A C T
This study analysed a submerged membrane bioreactor (SMBR) start-up with the purpose of determining the best conditions to carry it out. In order to do this, a hollow fibre membrane module was installed in a submerged configuration in a pilot aerobic reactor. The experiment was then divided in two phases, lasting 65 days each. During phase 1, the pilot plant was started-up without inoculum of activated sludge and no sludge, withdrawal was performed. Conversely, in phase 2, the MBR pilot plant was started-up with sludge inoculum and the sludge concentration was kept constant. In both phases, the volumetric loading rate applied to the pilot plant was kept constant. The authors analysed the difference in carbon removal performances, the evolution of floc sizes and the fouling rate in both phases. The results confirmed that MBRs can be quickly and easily started-up, but the initial start-up strategy can influence membrane fouling. More specifically, the carbon removal performances were similar in both phases, while the fouling rate increased faster during the start-up without inoculum, especially in terms of irreversible deposition of soluble compost on the membrane surface and into membrane pores.
\end{abstract}

(c) 2010 Elsevier B.V. All rights reserved.

\section{Introduction}

In conventional activated sludge systems (CASs), the start-up period represents a very important phase; most of the organic substrate in the influent wastewater cannot be biodegraded because the biomass concentration in biological reactors is very low at the

Abbreviations: $b_{\mathrm{H}}$, aerobic decay rate for the active biomass $\left[\mathrm{d}^{-1}\right]$; $b_{\mathrm{STO}}$, aerobic decay rate for stored compounds $\left[\right.$ day $\left.^{-1}\right]$; $f_{\mathrm{l}}$, fraction of inert material from endogenous respiration $\left[\mathrm{gCOD}_{\mathrm{XI}} \cdot g \mathrm{gOD}_{\mathrm{XBH}}^{-1}\right] ; f_{\mathrm{SI}}$, inert soluble substrate fraction from the hydrolysis of particulate matter $\left[\mathrm{gCOD}_{\mathrm{SI}} \cdot \mathrm{gCOD}-\mathrm{XS}^{-1}\right] ; J$, the permeate flux $\left[\mathrm{m}^{3} \mathrm{~m}^{2} \mathrm{~s}^{-1}\right] ; K_{\mathrm{S}}$, substrate half-saturation coefficient for heterotrophic biomass [ $\left.\operatorname{mgCOD~L}^{1}\right] ; K_{\text {STO }}$, half saturation

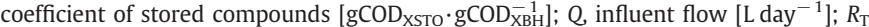
total resistance; $R_{\mathrm{m}}$, intrinsic membrane resistance; $R_{\mathrm{irr}}$, resistance due to irreversible deposition on the membrane surface and inside the pores; $R_{\mathrm{re}}$, resistance due to reversible deposition; $R_{\mathrm{PB}}$, resistance due to pore blocking; $R_{\mathrm{Cirr}}$ and $R_{\mathrm{Crev}}$, resistances due to irreversible and reversible cake deposition, respectively; $S_{\mathrm{SO}}$, dissolved substrate concentration in the influent [ $\left.\mathrm{mgCOD} \mathrm{L}^{-1}\right] ; S_{\mathrm{S}}$, dissolved substrate concentration in the biological reactor $\left[\mathrm{mgCOD} \mathrm{L}^{-1}\right] ; V$, reactor volume $[\mathrm{L}] ; X_{\mathrm{BHS}}$, active biomass concentration in steady state conditions $\left[\mathrm{mgCOD} \mathrm{L}^{-1}\right] ; X_{\mathrm{IO}}$, inert particulate matter concentration in the influent $\left[\mathrm{mgCOD} \mathrm{L}^{-1}\right] ; X_{\mathrm{l}}$, suspended inert matter concentration $\left[\mathrm{mgCOD} \mathrm{L}^{-1}\right] ; X_{\mathrm{SS}}$, suspended solids concentration $\left[\mathrm{mgCOD} \mathrm{L}^{-1}\right] ; X_{\mathrm{SO}}$, particulate matter concentration in the influent $\left[\mathrm{mgCOD} \mathrm{L}^{-1}\right]$; $Y_{\mathrm{STO}}$, soluble substrate conversion coefficient into stored compounds $\left[\mathrm{gCOD}_{\mathrm{XSTO}} \cdot \mathrm{gCOD}_{\mathrm{SS}}^{-1}\right] ; Y_{\mathrm{H}}$, stored compounds conversion coefficient into biomass $\left[\mathrm{gCOD}_{\mathrm{XBH}} \cdot \mathrm{gCOD}_{\mathrm{XSTO}}^{-1}\right] ; Y_{\mathrm{XBHS} / \mathrm{s}}$, conversion rate only related to the biological processes $\left[\mathrm{gCOD}_{\mathrm{P}} \cdot \mathrm{gCOD}^{-1}\right] ; Y_{\mathrm{XI} / \mathrm{S}}$, conversion rate related to the inlet inert matter accumulation $\left[\mathrm{gCOD}_{\mathrm{P}} \cdot \mathrm{gCOD}^{-1}\right] ; Y_{\mathrm{XSS} / \mathrm{S}}$, conversion rate observed under state conditions for the active biomass $\left[\mathrm{gCOD}_{\mathrm{P}} \cdot \mathrm{gCOD}^{-1}\right] ; \mu$, permeate viscosity [Pa s]; $\mu_{\mathrm{m}}$, maximum specific growth rate of active biomass [day ${ }^{-1}$ ].

* Corresponding author. Tel.: + 39 0916657720; fax: + 390916657749

E-mail addresses: dibella@idra.unipa.it (G. Di Bella),durantef@kochmembrane.com (F. Durante), mtorre@idra.unipa.it (M. Torregrossa), gviv@idra.unipa.it (G. Viviani).

1 Tel.: + 39 0916657742; fax: + 390916657749 . beginning. In order to increase the biomass concentration, a complete recycling of settled sludge from the final clarifier to the biological tank should be performed until steady state conditions are reached (3-4 $\left.\mathrm{g} \mathrm{L}^{-1}\right)$, in terms of total suspended solids or TSS. Such a procedure would require about one month, and therefore, new plants are usually started-up by inoculation with sludge from existing plants. In this way, the start-up of CAS may only last a few days [1,2].

On the other hand, membrane bioreactors (MBR) seem not to have any problem related to the start-up period, because the membrane is able to completely retain all of TSS within the reactor from the first days of use, thus allowing a quick increase of TSS concentration in the biological reactor [2]. Furthermore, membranes that are usually installed in wastewater treatment plants (micro or ultra filtration membranes) allow the complete removal of both the suspended and colloidal solids, in addition to partial removal of the dissolved organic matter from the influent wastewater, with a COD removal (by means of filtration alone) to $70 \%$ of the influent COD [2]. Thus, the final effluent is usually within the legal limits for carbon effluent concentration from the first days of operation and the initial growth of autotrophic bacteria is improved [3].

Recent studies focusing on the bioreactor start-up period [2,4-6] agree that the "spontaneous" start-up of membrane bioreactors is usually short and very easy to manage, such that an initial inoculum may not be required. Further, the initial activated sludge inoculum has been considered only for its positive effect on the optimization of biological nutrient removal and Anammox process start-up [7-9]. Regardless, it must be stressed that in such studies only the removal performances were carefully observed, and the consequences that different start-up procedures may have on the fouling development were neglected. 
Due to the fact that fouling phenomena and the consequent cleaning demand represent one of the main obstacles to the management of MBR plants [3], the aims of this work were to investigate the role of the initial activated sludge inoculum during the MBR start-up, paying attention to both system performances with regard to carbon removal (note: the start-up of denitrification in MBR is not the subject of this work) and the fouling increase. Additionally, the evolution of the floc dimensions and their effects on the membrane permeability were also investigated.

\section{Materials and methods}

The pilot plant consisted of a $190 \mathrm{~L}$ biologic reactor, in which a submerged hollow fibre Zenon ZW10 ${ }^{\circledR}$ module was installed (nominal surface, $0.93 \mathrm{~m}^{2}$; pores dimension, $0.04 \mu \mathrm{m}$ ). The complete pilot plant layout is represented in Fig. 1. The entire experiment lasted 130 days and was divided into two phases (65 days each) characterized by a different evolution of Mixed Liquor Suspended Solids (MLSS) concentrations:

- Phase 1 - During the first experimental phase, the pilot plant was started-up without any sludge inoculum. In this period no sludge withdrawal was performed, except for a negligible amount for sampling and an accidental biomass loss on day 56 .

- Phase 2 - During the second experimental phase, the pilot plant was started-up with sludge inoculum (initial MLSS concentration $=15 \mathrm{~g} \mathrm{TSS} \mathrm{L}^{-1}$ ). In this phase, the operating conditions of the pilot plant were slightly different compared to phase 1 , because it was necessary to periodically waste the surplus sludge in order to keep the biomass concentration in the pilot plant equal to the initial value. This operation was done in order to study the fouling development without excessive TSS concentration in the aerobic tank and with an approximately constant cake pre-filter effect.

In both phases a constant volumetric loading rate $(\mathrm{VLR}=1.1 \mathrm{~kg}$ COD m $\mathrm{m}^{-3} \mathrm{~d}^{-1}$ ) and hydraulic loading rate (HRT $=10$ hours) were applied to the pilot plant. Further, it is worth noting that for each experimental phase a new ZW10® module having the same characteristics was used.

The pilot plant was installed at the Palermo municipal wastewater treatment plant (WWTP); it was fed with real unsettled wastewater that passed through only a fine screen $(2 \mathrm{~mm}$ ) before entering the pilot plant. This mechanical pre-treatment allows the reduction of braid forming by hair and fibrous material [10]. In order to guarantee a constant volumetric loading rate, the wastewater was initially stored in two buffer tanks with a volume of 1500 L each. These tanks, completely mixed, allowed us to adjust the COD value by diluting the wastewater with tap water, if necessary. Thus, while one buffer tank was feeding the pilot plant, the COD was measured and fitted by dilution to the planned value $(500 \mathrm{mg} / \mathrm{L})$ in the other. The wastewater was not diluted when the COD concentration was less than $500 \mathrm{mg} / \mathrm{L}$ (i.e., days 7 and 40 in phase 1 and days 1, 2, 26 and 63 in phase 2) or when tap water was not available (i.e., day 51 in phase 1 , with a $\operatorname{COD}_{\text {tot }}$ concentration that reached $1,424 \mathrm{mg} / \mathrm{L}$; and day 19 in phase 2 with a real $\operatorname{COD}_{\text {tot }}$ concentration of $\sim 700 \mathrm{mg} / \mathrm{L})$. However, as shown in Table 1 , the average influent characteristics were comparable, especially the mean concentration in the first two weeks (the most important for the startup investigation). It should also be noted that the raw wastewater was taken upstream of the primary settling tanks, and it was characterised by a high concentration of suspended solids, both organic and inert. Additionally, the raw sewage quality was influenced by periodic discharges of a limited volume of industrial wastewater. However, the characteristics of the influent used in the two phases were only different in the percentage of the particulate biodegradable organic matter and particulate inert organic matter, as shown in the COD fractions in the inlet wastewater (Table 2). Conversely, the nitrogen compounds in the two influents, especially $\mathrm{NH}_{4}-\mathrm{N}$ and $\mathrm{NO}_{3}-\mathrm{N}$, were more variable. Nevertheless, as discussed above, we were not investigating the nitrogen removal performance of the pilot plant (no denitrification phase), and the quality of inlet wastewater (in terms of COD and nitrogen) was only slightly influenced during the first 10 days. Referring to permeate production, a hydraulic ram pump connected to the upper part of the module allowed permeate extraction in out-in mode and its subsequent accumulation in the permeate tank. In order to monitor the transmembrane pressure applied to produce the design flux an analogical vacuum meter was installed on the permeate line. The durations of suction and backwash were set to 9 and 1 min respectively, and they were never changed. In this way, the gross permeate flux extracted by the pump during the suction was equal to $21 \mathrm{~L} \mathrm{~m}^{-2} \mathrm{~h}^{-1}$; consequently, the net permeate flux was equal to $18.9 \mathrm{~L} \mathrm{~m}^{-2} \mathrm{~h}^{-1}$. Additionally, the pilot plant was equipped with a double aeration system. The first one consisted of a blower and two fine bubbles spargers installed at the bottom of the bioreactor, providing the aerobic conditions for the biological oxidation of organic compounds and ammonium. The second, a coarse bubble sparger, was built inside the membrane module with the purpose of limiting the accumulation of foulants on the fibre surface [11].

Throughout the two experimental phases, the plant ran continuously, and no chemical cleaning of the module was carried out (only a physical cleaning was done on the 52nd day).

During the first week of operation, in both experimental phases, the analyses of $\mathrm{COD}_{\text {tot }}, \mathrm{COD}_{\text {sol }}$, BOD, TSS, VSS, N-NH, $\mathrm{N}_{4}-\mathrm{NO}_{2}$ and $\mathrm{N}-$ $\mathrm{NO}_{3}$ were carried out on the influent, mixed liquor and effluent, three times a week. Temperature, $\mathrm{pH}$ and dissolved oxygen in the biological reactor were also measured every day. Moreover, microbiological analyses were carried out once a week in order to test the membrane capability of retaining the indicator bacteria (Escherichia coli). All of

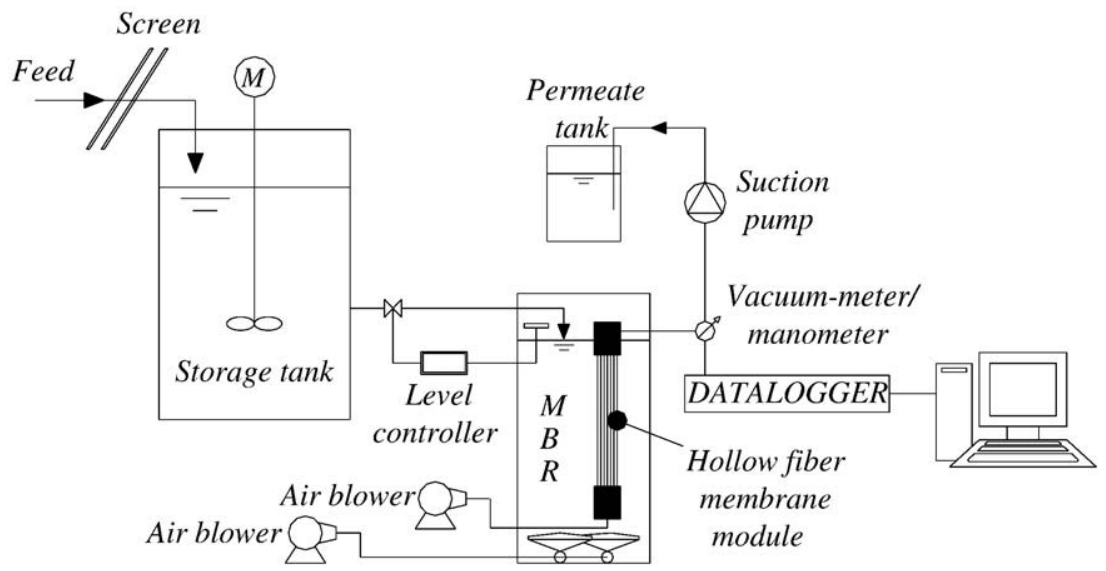

Fig 1. Pilot plant layout. 
Table 1

Influent wastewater features in both start-up phases.

\begin{tabular}{llllllllll}
\hline & $\begin{array}{l}\mathrm{COD}_{\text {tot }} \\
\mathrm{mg} / \mathrm{L}\end{array}$ & $\begin{array}{l}\mathrm{COD}_{\text {sol }} \\
\mathrm{mg} / \mathrm{L}\end{array}$ & $\begin{array}{l}\mathrm{BOD}_{5} \\
\mathrm{mg} / \mathrm{L}\end{array}$ & $\begin{array}{l}\mathrm{TSS} \\
\mathrm{mg} / \mathrm{L}\end{array}$ & $\begin{array}{l}\mathrm{VSS} \\
\mathrm{mg} / \mathrm{L}\end{array}$ & $\begin{array}{l}\mathrm{N}^{-\mathrm{NH}_{4}} \\
\mathrm{mg} / \mathrm{L}\end{array}$ & $\begin{array}{l}\mathrm{N}-\mathrm{NO}_{2} \\
\mathrm{mg} / \mathrm{L}\end{array}$ & $\begin{array}{l}\mathrm{N}-\mathrm{NO}_{3} \\
\mathrm{mg} / \mathrm{L}\end{array}$ & $\begin{array}{l}\mathrm{N}-\mathrm{N}_{\text {tot }} \\
\mathrm{mg} / \mathrm{L}\end{array}$ \\
\hline Phase 1 & 527 & 177 & 227 & 294 & 249 & 48 & $<0.02$ & $<0.05$ & 49 \\
Phase 2 & 510 & 134 & 255 & 270 & 262 & 36 & 0.07 & 0.78 & 54 \\
\hline
\end{tabular}

Table 2

The COD fractions of the inlet wastewater.

\begin{tabular}{lcc}
\hline Parameter & $\begin{array}{l}\text { Phase I } \\
{[\%]}\end{array}$ & $\begin{array}{c}\text { Phase I } \\
{[\%]}\end{array}$ \\
\hline$S_{\mathrm{S}}=$ soluble biodegradable substrate (RBCOD) & 15 & 17 \\
$S_{\mathrm{I}}=$ soluble inert organic matter & 6 & 6 \\
$X_{\mathrm{S}}=$ particulate biodegradable organic & 32 & 42 \\
$\quad$ matter (RHCOD + SBCOD) & & \\
$X_{\mathrm{I}}=$ particulate inert organic matter & 42 & 28 \\
Active fraction & 5 & 7 \\
\hline
\end{tabular}

the chemical-physical analyses were performed according to standard methods [12].

Finally, during the entire experimental period, the evolution of the activated sludge floc morphology was monitored 2-3 times per week. This analysis was carried out via electronic sifting by Granix ${ }^{\text {TM }} 5.0$ software (Microvision Instruments) that, by means of an image analysis technique, is able to determine the granulometric features of a population. In order to properly compare of all the microscopic observations, each biomass sample was preliminarily diluted with permeate to a final concentration of 3 gTSS L $^{-1}$. The microscopic analyses of the activated sludge flocs were carried out with a Leica phase contrast microscope (DM-LB-100) connected to a digital camera. Each sample was analysed with an enlargement of $100 \times$ by taking several consecutive photos covering an area of $10 \mathrm{~mm} \times 4 \mathrm{~mm}$. Afterwards, all images were merged by means of PHOTOSHOP-CS ${ }^{\mathrm{TM}}$ software to obtain one digital image. Such a method allowed us to include a large number of particles in a single image, and only the particles that were completely captured in the image were taken into account in the following step. Finally, the images were analysed via Granix $^{\mathrm{TM}}$ software, which uses the granulometry through opening technique to identify the mean size of the particles [13]. Granix ${ }^{\mathrm{TM}}$ also provides most of the statistics of the population, such as mean and characteristics diameters $\left(d_{\mathrm{m}}\right)$, mode, standard deviation, max, min, and some splitting limits $\left(d_{10}, d_{50}, d_{75}\right.$ and $\left.d_{90}\right)$.

\section{Results and discussion}

\subsection{Pilot plant performances}

The removal efficiencies for both phases are reported (averages of each phase) in Table 3 . The average removal efficiency for the organic matter was $90 \%$ or more in both phases. In particular, the COD (total and soluble) and BOD concentrations in the effluent were within the Italian standards for the reuse of treated wastewater from the first day of both experimental phases.

More specifically, in the first day of phase 1 the $\mathrm{COD}_{\text {tot }}$ and $\mathrm{COD}_{\text {sol }}$ removal were about $75 \%$ and $25-30 \%$, respectively. Such a highquality performance in total COD removal, was mainly due to the membrane which worked as a physical barrier towards all the pollutants with average dimensions bigger than the pores. Thus, when the biomass concentration in the aerobic tank was low and the biodegradation was negligible, the membrane retained all particular $\mathrm{COD}_{\text {tot }}$ (about two thirds of the total COD in the influent, see Table 1) and only removed a part of the soluble COD (in the range of 0.04$0.45 \mu \mathrm{m}$, respectively membrane pores and porosity of filters used in the laboratory for soluble COD determination).
Table 3

Pollutant removal performance in both phases.

\begin{tabular}{|c|c|c|c|c|c|c|}
\hline \multirow[b]{2}{*}{ Parameter } & \multicolumn{3}{|l|}{ PHASE 1} & \multicolumn{3}{|l|}{ PHASE 2} \\
\hline & $\begin{array}{l}\text { Influent } \\
{\left[\mathrm{mg} \mathrm{L}^{-1}\right]}\end{array}$ & $\begin{array}{l}\text { Effluent } \\
{\left[\mathrm{mg} \mathrm{L}^{-1}\right]}\end{array}$ & $\eta[\%]$ & $\begin{array}{l}\text { Influent } \\
{\left[\mathrm{mg} \mathrm{L}^{-1}\right]}\end{array}$ & $\begin{array}{l}\text { Effluent } \\
{\left[\mathrm{mg} \mathrm{L}^{-1}\right]}\end{array}$ & $\eta[\%]$ \\
\hline COD & 527 & 47 & 91 & 510 & 31 & 94 \\
\hline $\mathrm{COD}_{\text {sol }}$ & 177 & 34 & 79 & 134 & 23 & 81 \\
\hline $\mathrm{BOD}_{5}$ & 227 & 10 & 95 & 255 & $<10$ & $>97$ \\
\hline $\mathrm{N}-\mathrm{NH}_{4}$ & 48 & $4\}$ & $\eta_{\text {nit }}=92$ & 35.8 & $0.4\}$ & $\eta_{\text {nit }}=98$ \\
\hline $\mathrm{N}-\mathrm{NO}_{3}$ & $<0.05$ & $34^{J}$ & & 0.78 & 36 & \\
\hline $\mathrm{N}_{\mathrm{TOT}}$ & 49 & 41 & 14 & 53.9 & 50.3 & 6.5 \\
\hline SST & 294 & 0 & 100 & 274 & 0 & 100 \\
\hline E. coli & 4610714 & 0.4 & 99.99998 & $2,664,286$ & 0 & 100 \\
\hline
\end{tabular}

Aside from the barrier effect, the biological effect was active during phase 2 (with inoculum) due to the biomass seeded in the bioreactor. Thus, from the very beginning, even though the micro-organisms were not perfectly acclimatised, their concentration was high enough to assure efficient biological removal. As a consequence, the organic matter concentration in the effluent was lower than during the first days of phase 1, with a total and soluble COD removal of 85 and $75 \%$ respectively, on the day 1 .

Obviously, during the start-up without inoculum, the biomass concentration in the pilot plant continuously increased, as did the carbon removal performance as a consequence. Thus, at the end of phase 1 , the mean organic concentration in the permeate became similar to that in phase 2. Finally, the overall depurative biological contribution in the two phases was similar.

The filtration process even played a relevant role in the nitrification process [2,14], as shown in Fig. 2. However, as discussed above, the $\mathrm{NH}_{4}-\mathrm{N}$ and $\mathrm{N}_{\text {tot }}$ concentrations in the influent were different, but some interesting aspects could be analysed during this experiment, especially for the nitrification process in the first days. More specifically, the membrane allowed the complete retention of all suspended solids and a part of the soluble matter. In this context, autotrophic bacteria can be also retained in the reactor, the autotrophic bacteria concentration can quickly increase, and consequently, the nitrification phenomenon can be accelerated. In particular, during phase 1 , almost complete ammonia nitrogen oxidation occurred after only 1 week. This confirmed the fundamental role played by the membrane module in keeping all of the inlet micro-organisms inside the biological reactor, allowing a faster increase of the slowgrowing micro-organisms as well.

To understand why complete nitrification occurred from the first experimental day using the start-up with sludge inoculum, the initially high concentration of the biomass $\left(\sim 15 \mathrm{~g} \mathrm{~L}^{-1}\right)$ has to be considered in addition to the filtration process just described. That is why the nitrification efficiencies were so different at the beginning of the two phases, as shown in Table 3.

Although the plant configuration was conceived only for organic carbon removal (i.e., no anoxic tank was used), a partial denitrification process occurred during phase 1 anyway, as shown by the $\mathrm{N}_{\text {tot }}$ data in Table 3 and in Fig. 2a, where there is a clearly visible gap between $\mathrm{NH}_{4}($ in $) \approx \mathrm{N}_{\text {tot }}($ in $)$ and $\mathrm{N}_{\text {tot }}$ (out). This phenomenon was related to the accidental formation of a dead anoxic zone at the bottom of the reactor, where the biomass settled. During phase 2, this unintentional denitrification process was largely reduced due to periodical anoxic sludge withdrawal from the bottom of the reactor. Thus, in this phase, the nitrogen removal was mainly due to biological assimilation by bacteria for cellular synthesis processes.

In conclusion, comparing the results of the two experimental phases, it should be noted that the permeate quality was slightly higher in phase 2 . However, for both different inoculum procedures, the permeate stayed within the legal limits for several parameters $\left(\mathrm{COD}_{\text {tot }}, \mathrm{BOD}_{5}\right.$, TSS and $E$. coli) except total nitrogen, because the pilot plant layout had no specific denitrification stage. 

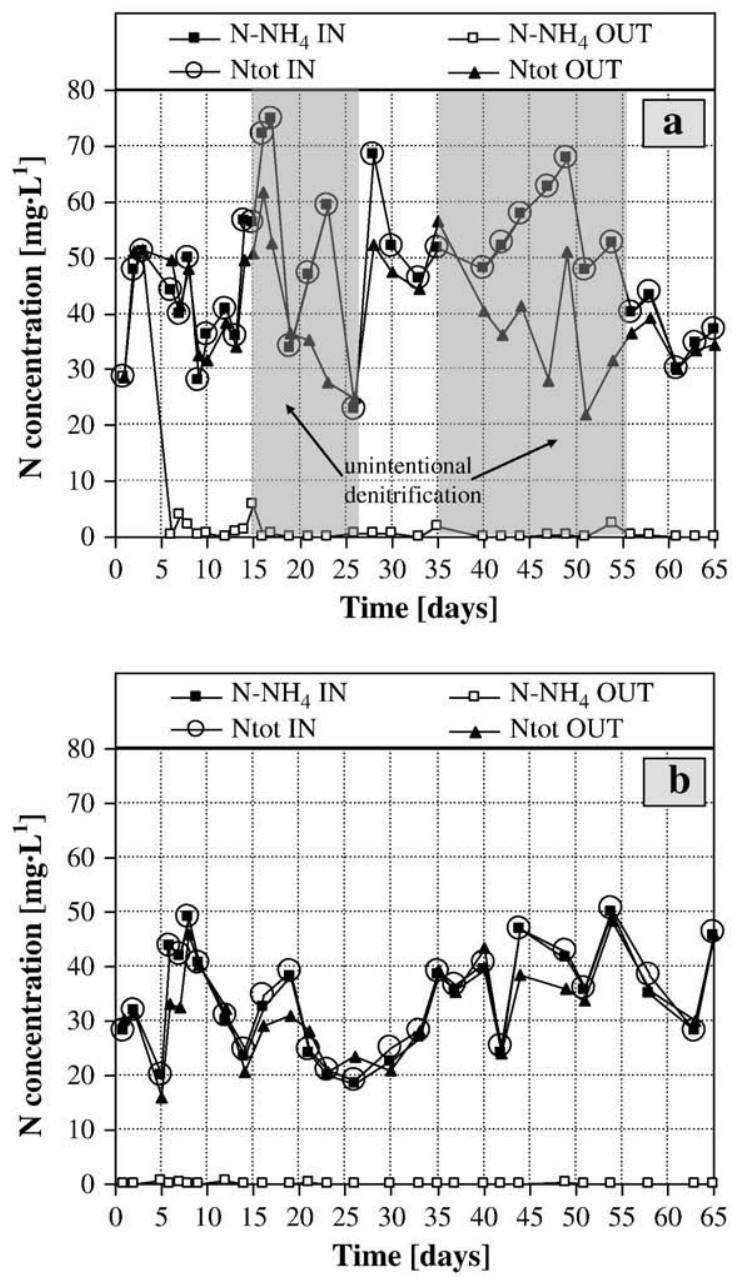

Fig. 2. $\mathrm{N}-\mathrm{NH}_{4}, \mathrm{~N}-\mathrm{NO}_{2}$ and $\mathrm{N}-\mathrm{NO}_{3}$ concentration in the influent and effluent during start-up without (a) and with inoculum (b).

\subsection{MLSS increase during start-up with and without inoculum}

The biomass concentration trend in the pilot plant during the two experimental phases was monitored by means of TSS and VSS concentrations. Fig. 3 ( $a$ and $b$ ) shows the TSS and the VSS/TSS ratio for both phases; the latter is useful to evaluate if any inert matter accumulation occurred in the biological sludge. As shown in Fig. 3, the growth of the suspended solids inside the reactor in the two experimental phases was very different, due to the different operating conditions applied. During phase 1 raw wastewater was used to fill the reactor on the first day. Thus, the initial suspended solid concentration was the same as the raw wastewater. Further, it constantly increased because the biomass was completely retained inside the reactor by the membrane and no sludge withdrawal was carried out. At the end of phase 1 , a TSS concentration higher than 20 gTSS L $^{-1}$ was achieved. On the contrary, in phase 2 , the biomass concentration was kept almost constant ( $15 \mathrm{gTSS} \mathrm{L}^{-1} \pm 1 \mathrm{~g} / \mathrm{L}$ ) thanks to periodical sludge removal. Nevertheless, the control of TSS concentration growth was not simple. However, after the acclimatisation of the inoculated biomass and the stabilization of biological conditions, the sludge withdrawal was fixed at a constant daily value $(6 \mathrm{~L})$. In this condition, the sludge retention time (SRT) was roughly constant, i.e., about 3235 days (after the 25 th day).

In phase 1 (see Fig. 3a), there were two seeming stabilizations in the sludge concentration: a very short one from day 18 to day 26 , and a more evident one from day 35 to day 50 . However, it was observed that particulate matter accumulation occurred in the dead part at the
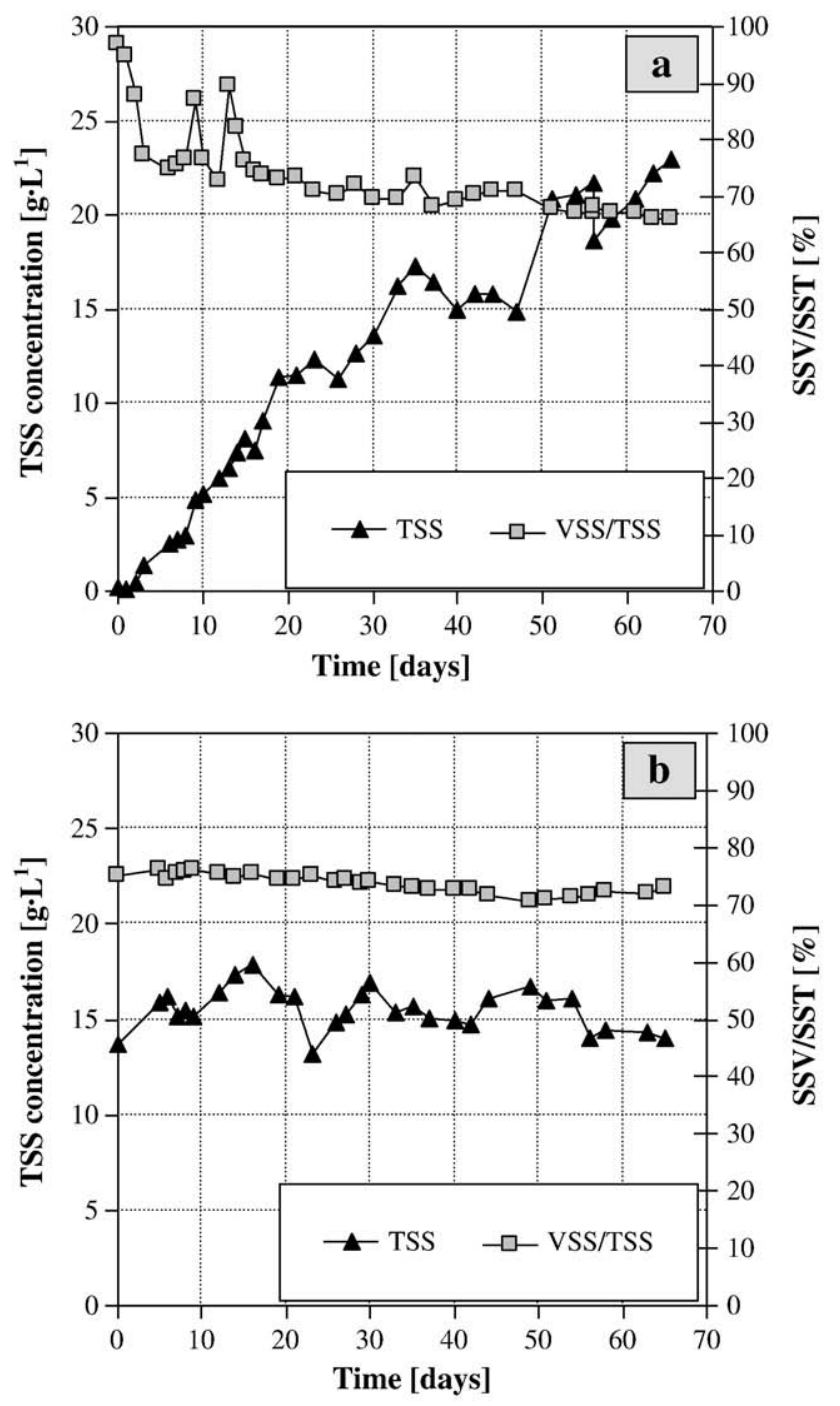

Fig. 3. TSS increase during start-up without (a) and with inoculum (b).

bottom of the reactor, below the air spargers, in both instances. Due to this, that amount of biomass was not included in the suspended solids measurements. The mixing of the settled particles in this dead zone showed that, during entire experiment without inoculum, the suspended solid concentration continuously increased, and the apparent stabilizations were actually only due to imperfect mixing in the reactor. The presence of this dead zone also explained why, inside an aerobic reactor, a partial unintentional denitrification phenomenon was observed.

Near the end of phase 1 (56th day), an accidental malfunction led to a biomass loss from the pilot plant. Regardless, during the following days, the suspended solid concentrations began to increase again, reaching a value of $22 \mathrm{gTSS} \mathrm{L}^{-1}$ on the last experimental day. Because a constant VLR was applied to the pilot plant, and the biomass was completely retained inside the reactor, a constant decrease of the organic loading rate (OLR) was observed. Moreover, in the second half of phase 1 the OLR was always less than $0.1 \mathrm{gCOD} \mathrm{gVSS}^{-1} \mathrm{~d}^{-1}$, and despite this stable parameter, a stable value for the TSS was never achieved. Similar results were also found by Pollice et al. [5].

The VSS/TSS ratio in phase 1 showed a large decrease from the initial average value of $0.85 \pm 0.1$ during the first week to an average value of $0.67 \pm 0.01$ during the last week. Thus, the lack of sludge withdrawal caused a progressive accumulation of inorganic matter inside the bioreactor; however, analyses of system performance 
suggested that this progressive accumulation of inorganic matter had no significant negative influence on the performances.

In order to evaluate the biomass growth during phase 1 , sludge production was measured through the observed yield coefficient $Y_{\mathrm{obs}}$, which represents the biomass production per gram of COD removed. This coefficient was calculated as the ratio between the VSS accumulated in the reactor and the overall quantity of COD removed [15]. The VSS values used for the calculation refer only to those analysed when the reactor was completely mixed, and take also into account the biomass loss that occurred on the 56th day.

The yield coefficient slowly decreased with the increase of VSS concentration in the biological reactor and with the consequent decrease of OLR. In the last 15 days of the experiment, the $Y_{\text {obs }}$ reached a stable value of $0.24 \pm 0.03 \mathrm{gVSS}_{\mathrm{gCOD}} \mathrm{rem}^{-1}(0.32 \pm 0.04 \mathrm{gCOD}$ $\left.\mathrm{gCOD}_{\mathrm{rem}}{ }^{-1}\right)$, significantly lower than the typical value in a conventional activated sludge plant $[16,17]$ but higher than the values observed in other experimental studies on MBR plants $[5,6]$. This result may be due to the wastewater inlet point chosen in the municipal plant to feed the pilot and to the subsequent high percentage of inert matter (see Table 2). Thus, the inert matter in the influent wastewater was obviously included in the observed yield coefficient because it contributed to sludge production.

In order to eliminate the contribution of influent inert matter from the observed yield coefficient, $Y_{\text {obs }}$ was written as the sum of: (i) a conversion rate directly related to the overall biological processes $\left(Y_{\mathrm{XBHS} / \mathrm{S}}\right)$ and (ii) the progressive inert matter accumulation from the influent $\left(Y_{\mathrm{XI} / \mathrm{S}}\right)$ :

$Y_{\mathrm{XSS} / \mathrm{S}}=Y_{\mathrm{XBHS} / \mathrm{S}}+Y_{\mathrm{XI} / \mathrm{S}}$

Starting from the ASM3 model under the hypothesis of limiting substrate concentration and stable active biomass concentration [18], it is possible to write Eq. (1) as follows:

$Y_{\mathrm{XSS} / \mathrm{S}}=\frac{f_{i} \cdot b_{\mathrm{H}} \cdot X_{\mathrm{BHS}}}{\frac{Q}{V}\left[\left(S_{\mathrm{S} 0}-S_{\mathrm{S}}\right)+\left(1-f_{\mathrm{SI}}\right) \cdot X_{\mathrm{S} 0}\right]}+\frac{X_{\mathrm{I} 0}}{\frac{Q}{V}\left[\left(S_{\mathrm{S} 0}-S_{\mathrm{S}}\right)+\left(1-f_{\mathrm{SI}}\right) \cdot X_{\mathrm{S} 0}\right]}$.

Eq. (2) is based on the ASM3 model, taking into account all the mass balances referring to the storage of soluble substrate, the particulate fraction of the substrate, the consumption of stored products, the active biomass concentration, the inert accumulation in the system and the oxygen demand. Furthermore, only the aerobic heterotrophic microorganisms were taken into account, and the oxygen concentration, nitrogen concentration, etc., were not considered limiting factors.

Moreover, because it is difficult to imagine that in a reactor operating under limiting substrate conditions (like the pilot plant) a potential substrate may accumulate, it was assumed that the particulate fraction of the influent substrate had a hydrolysis velocity equal to the loading rate of the biodegradable substrate to be hydrolyzed. Starting from all of these considerations, it is possible to express the active biomass threshold concentration in steady state conditions with Eq. (3):

$X_{\mathrm{BHS}}=\frac{\frac{Q}{V}\left[\left(S_{\mathrm{SO}}-S_{\mathrm{S}}\right)+\left(1-f_{\mathrm{SI}}\right) \cdot X_{\mathrm{SO}}\right]}{\frac{b_{\mathrm{H}}}{Y_{\text {STO }}}\left(\frac{1}{Y_{\mathrm{H}}}+\frac{b_{\text {STO }} \cdot K_{\text {STO }}}{\mu_{\mathrm{m}}-b_{\mathrm{H}}}\right)}$

Thus, the threshold value given by Eq. (3) depends on the organic volumetric loading rate applied to the system and on the typical kinetic parameters of the bacterial population that uses a given substrate. The kinetic constants were evaluated with a respirometric batch test $\left(\mu_{\mathrm{m}}=0.65\right.$ days $^{-1} ; Y_{\mathrm{H}}=0.74 \mathrm{gCOD}_{\mathrm{gCOD}}{ }^{-1} ; b_{\mathrm{H}}=0.29$ day $^{-1}$; and $K_{\mathrm{S}}=0.61 \mathrm{mgCOD} \mathrm{L}^{-1}$ ). From Eqs. (2) and (3), using either the results from the respirometric analysis or the default values of the ASM3 model (when the experimental values were not available), it is possible to evaluate the two terms in which the yield coefficient of the system were divided:

$Y_{\mathrm{XSS} / \mathrm{S}}=Y_{\mathrm{XBHS} / \mathrm{S}}+Y_{\mathrm{XI} / \mathrm{S}}=0.09+0.23=0.32 \mathrm{gCOD} \cdot \mathrm{gCOD}^{-1}$.

In conclusion, the sludge production was apparently higher than that usually reported for MBR plants, and this result seems to contradict one of the most important advantages of MBR systems, i.e., the low sludge production. In fact, the application of the ASM model demonstrated that $70 \%$ of the actual sludge production was due to the accumulation of the inert matter coming from the unsettled wastewater. Thus, the sludge production only related to the biological processes, which is in good agreement with the values reported in previous experimental studies carried out in similar operating conditions where pre-settled or synthetic wastewater was used $[5,6]$.

Fig. 4 shows the $Y_{\text {obs }}$ value and the net TSS mass accumulated in the tank during phase 1 .

Referring to phase 2, the suspended solid concentrations in the bioreactor were previously shown in Fig 3b. As already mentioned, the pilot plant was inoculated on the first day of the experiment with 15 gTSS $\mathrm{L}^{-1}$ activated sludge, and a similar value was maintained almost constantly during phase 2 via periodic sludge removal. In this phase, the VSS/TSS ratio was different from the one measured in phase 1 ; it was almost constant (average value of $0.74 \pm 0.03$ ) due to the sludge removal, which prevented the progressive accumulation of inert compounds in the bioreactor.

\subsection{Analysis of floc dimensions}

MBR plants often work under low organic loading rate conditions such that the biomass prefers growing in dispersed form (small flocs and free bacteria) in order to have better access to the substrate $[19,20]$. Furthermore, the high turbulence in membrane bioreactors leads to mechanical deflocculation that reduces floc aggregation and breaks apart large flocs if they are present. In particular, the high turbulence in submerged MBRs is mainly caused by the coarse bubbles aeration system which generates strong turbulence to continuously clean the membrane surface [21-23].

The results of the morphology observations, according to the previous description, are reported in Fig. 5, where the mean floc dimensions trends are shown for both phases, without and with inoculums, as well as the $d_{10}$ and $d_{90}$ data.

Considering phase 1 , even though the interpretation is quite complicated, it seems that the biological aggregates initially reached considerable dimensions (compared to the usual dimensions of biological aggregates in MBRs). This phenomenon was likely due to the operating conditions at the beginning of the phase; the very low

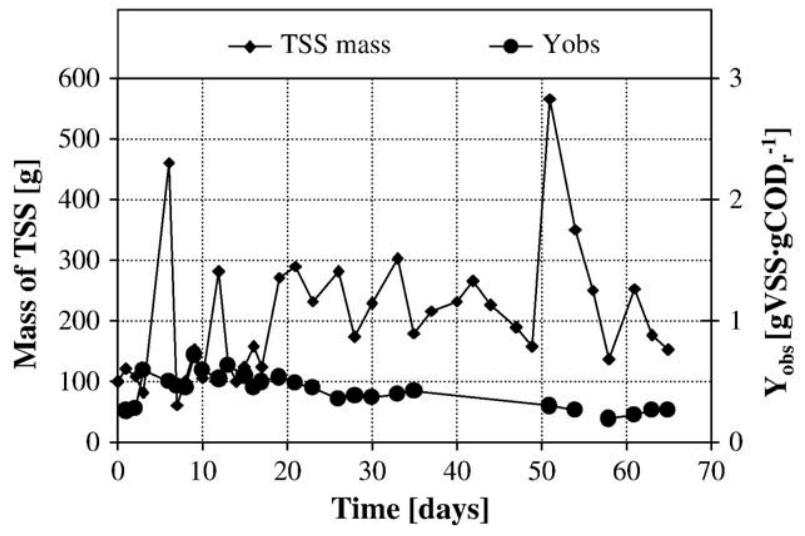

Fig. 4. OLR, VSS and $Y_{\mathrm{obs}}$ during phase 1 (with complete sludge retention). 

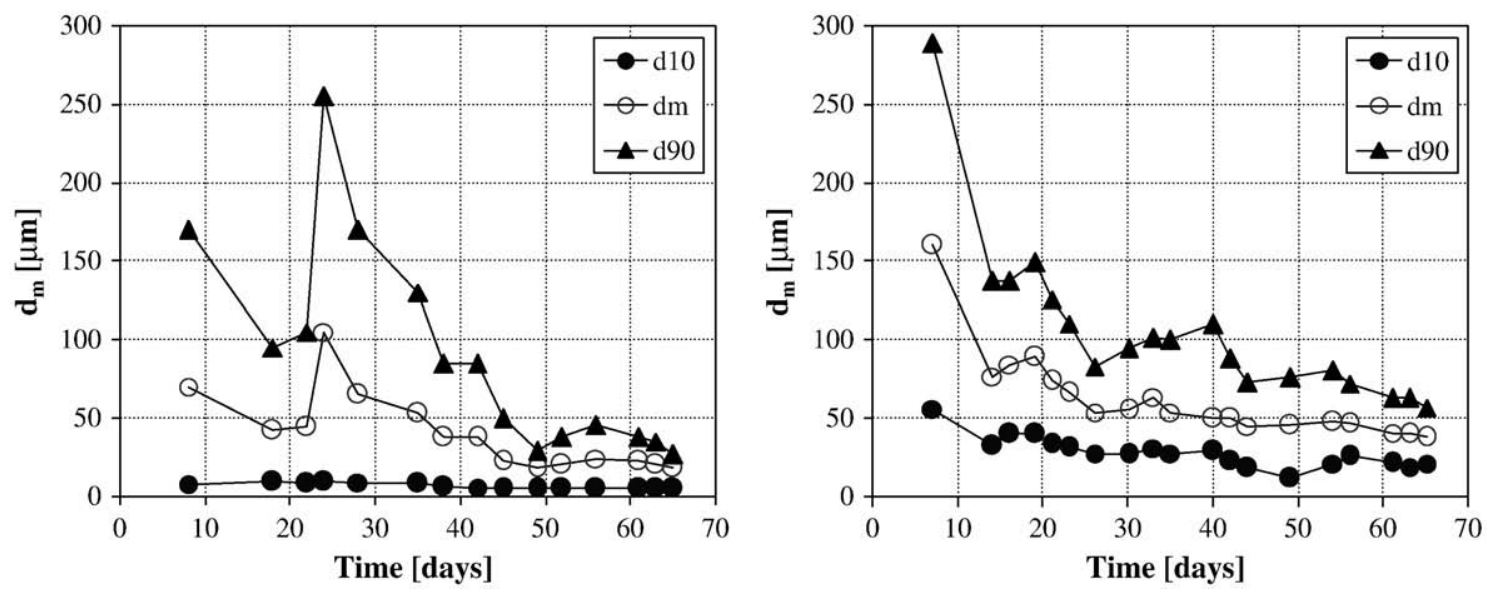

Fig. 5. Floc dimension variations in both start-ups.

biomass concentration in the first days enabled a high organic loading rate in the pilot plant. In particular the food to microorganism ratio (F/M) decreased from $6.4 \mathrm{gCOD} \mathrm{gVSS}^{-1} \mathrm{day}^{-1}$ on the first day to 0.2 gCOD gVSS ${ }^{-1}$ day $^{-1}$ on day 17 . Obviously, these values do not imply any difficulty in substrate assimilation by the micro-organisms [24]. Unfortunately, the dimensions of the flocs that were analysed were not representative because the reactor was poorly mixed. The real average dimensions of the flocs were determined only after the fine bubbles aeration system was upgraded (on the 24th day) because the previously settled sludge was re-suspended in the tank. After the aeration system upgrade, a slow decrease of the floc dimensions was observed in the floc dimensions versus time curve (Fig. 5 - phase 1). At the end of phase 1 the average size of the flocs was $\sim 20 \mu \mathrm{m}$, which is a very low value compared to the CAS plants, thus confirming the results of Smith et al. [25] and Merlo et al. [26]. This deflocculation phenomenon was likely due to the operating conditions: as the biomass concentration increased, the $\mathrm{F} / \mathrm{M}$ ratio during phase 1 constantly decreased to $0.07 \mathrm{gCOD}_{\mathrm{gVSS}}{ }^{-1} \mathrm{day}^{-1}$. This famine state may have been caused by extrapolymer substance (EPS) assimilation by the biological aggregates, such that the floc structures became very fragile. Then, the flocs were disrupted by the mechanical stress due to high turbulence, according to [26]. In particular, after upgrading the aeration system, the local shear intensity $G$ was $240 \mathrm{~s}^{-1}$ (i.e., greater than typical values in the CAS that rarely exceed $200 \mathrm{~s}^{-1}$ [21]). In general, the observations carried out to evaluate the average floc dimensions are confirmed by the $d_{10}$ and $d_{90}$ trend. However, the analysis of the latter characteristic diameters underscores some important aspects. First, the $d_{90}$ values indicate how the increase in the aeration system power at day 24 had a strong effect on the immediate re-suspension of the larger particles that previously settled. Indeed, the dimension of such particles (referring to the $d_{90}$ ) increased too quickly compared to the expected value, consequent to the flocculation phenomenon related to the organic load applied to the pilot system in that period. On the other hand, the "small particle" class did not show any change during the same period. Further, the data analysis showed that such granulometric analysis has poor sensitivity for particles with diameters lower than $5 \mu \mathrm{m}$. Hence, with the same $d_{10}$ percentage value, no reliable information can be obtained for the actual presence of particles in the range of $1-3$ or $4-5 \mu \mathrm{m}$.

Considering phase 2, the sludge to inoculate the MBR pilot was taken from the recirculation line of the municipal plant, so the initial concentration in the pilot plant was $15 \mathrm{~g} \mathrm{~L}^{-1}$ and was maintained between $15-16 \mathrm{~g} \mathrm{~L}^{-1}$ for the entire phase. In this phase, the $\mathrm{F} / \mathrm{M}$ ratio was $\sim 0.07 \mathrm{gCOD} \mathrm{gVSS}^{-1} \mathrm{day}^{-1}$ from the first days, and the parameter $G$ in the reactor was maintained at $\sim 255 \mathrm{~s}^{-1}$. At the beginning, the floc dimensions were similar to those from a CAS due to the inoculum. In particular $\sim 75 \%$ of the inoculated sludge was composed of flocs whose dimensions varied between from 100 to
$400 \mu \mathrm{m}$. Under these operating conditions, the turbulence action caused progressive deflocculation: as shown in Fig. 5, the floc dimensions at the end of phase 2 reached $\sim 40 \mu \mathrm{m}$. In such second experimental period, even the $d_{10}$ and $d_{90}$ trend underline the establishment of a regular and progressive deflocculation phenomenon (with almost constant organic load and $G$ values) of both large and small particles (though a slower diameter reduction was observed for the latter). The comparison between the two phases shows that, in both start-ups, deflocculation phenomena (biological and mechanical) took place. It should also be noted that in phase 1 , before reaching stationary conditions, a slight flocculation occurred when the OLR was still high.

Finally, we must stress that, in order to validate the analysis, the adopted procedure (opening technique) was compared with the results obtained in the "sieve analysis" test that was applied to a silt-clay sample. The obtained results were generally in good agreement, but two fundamental aspects have to be taken into account to apply this technique to activated sludge samples: (1) the opening technique application implies a strict image and contrast regulation in order to reduce the error during activated sludge flocs and dispersed particles analysis; and (2) the application of such a procedure to mixed liquor samples (considering the dimensions of the analyzed particles) requires a huge number of microscopic pictures (200-300 images, with a $100 \times$ zoom, to overlap a $40 \mathrm{~mm}^{2}$ area) that have to be further joined together to produce a single picture from which to work.

\subsection{The role of specific fouling mechanisms}

Fouling investigation is generally based on the determination of membrane permeability variations and on the evaluation of superficial deposition onto the membrane surface either during the operation of an MBR plant or during laboratory filtration tests $[27,28]$. Several authors base the fouling estimation on different components of the resistance to the permeation, each related to a specific fouling mechanism. According to the resistance in series model, the sum of these components is the total resistance [29-31]. The general formula of a specific resistance is based on Eq. (5) [31-33]:

$R=\frac{T M P}{J \cdot \mu}$.

Assuming that $\mu$ is equal to the water viscosity at $20^{\circ} \mathrm{C}$, the resistance value depends both on transmembrane pressure and permeate flux variations. Because, in this study the permeate flux was kept constant (constant flux strategy), the fouling rate was only determined by means of TMP variations during both phases. Otherwise a simultaneous variation of the two parameters would have affected foulant deposition 
and the specific fouling mechanisms [34]. Two different concepts of resistances were used, in both phases, for the characterization of fouling mechanisms: reversible/irreversible resistances for phenomenological classification [29,35-37] and cake deposition/pore blocking resistances in term of physical mechanisms of deposition [31,35,38].

In the first classification, the reversible resistances are defined by means of the amount of TMP recovered after periodic backwashes, while the irreversible resistances are defined through the amount of TMP that is recoverable only after an intensive physical or chemical cleaning $[3,29,33]$. In the second classification, the resistances are related to two different foulant depositions: the adsorption and deposition within the pores or onto the membrane surface. If the foulants are larger than the membrane pores, they cannot enter the pores, instead forming a cake layer on the membrane surface, and cake deposition occurs. This mechanism defines a mainly reversible type of fouling $[31,39]$. In practice, a low percentage of cake deposition resistance can be irreversible but several studies neglect it $[29,39,40]$. Conversely, if foulants have comparable or smaller sizes than the membrane pores (like soluble and colloidal matter) pore blocking occurs $[3,38]$, which is typically irreversible and can be removed only via chemical cleaning $[36,38]$. In order to evaluate the total resistance, another component must be determined, i.e., the intrinsic membrane resistance, which can be calculated by the following equation [27,31]:

$R_{\mathrm{m}}=\frac{T M P_{\mathrm{H}_{2} \mathrm{O}}}{J_{\mathrm{H}_{2} \mathrm{O}} \cdot \mu}$

where $\mathrm{TMP}_{\mathrm{H}_{2} \mathrm{O}}$ is the TMP in tap water filtration with flux $J_{\mathrm{H}_{2} \mathrm{O}}$ equal to $21 \mathrm{~L} \mathrm{~m}^{-2} \mathrm{~h}^{-1}$

$R_{\mathrm{m}}$ was measured at the beginning of both phases because two different ZW10 hollow fibres modules were used.

In order to investigate the fouling development, the total resistance $\left(R_{\mathrm{T}}\right)$ of one filtration cycle was analysed once a day during both phases. In particular, using a total resistance versus time diagram, it is possible to quantify the irreversible and reversible resistance in one suction phase between two consecutive backwashes [41]. The resistance value was calculated by means of Eq. (5), using the TMP values recorded by the datalogger. Fig. 6 shows an example of a typical filtration curve as well as the quantification of the irreversible and reversible components of the resistance, based on the following equations:

$R_{\mathrm{irr}}=\frac{T M P^{*}}{J \cdot \mu}-R_{\mathrm{m}}$

$R_{\mathrm{rev}}=\frac{T M P}{J \cdot \mu}-\frac{T M P^{*}}{J \cdot \mu}$

where TMP* is the starting TMP value of the suction phase analysed.
More specifically, Fig. 6 shows that the initial resistance is equal to the sum of the membrane resistance $\left(R_{\mathrm{m}}\right)$ and the irreversible resistance $\left(R_{\text {irr }}\right)$ due to the fouling not removed by the previous backwash. Obviously, as $R_{\mathrm{m}}$ is known, $R_{\mathrm{irr}}$ is directly calculable. Thus, the resistance trend in a typical filtration cycle is characterised by a first phase with a fast increase, which represents a "transition stage" mainly due to the initial superficial deposition that slowly covers the membrane surface. After $50-70 \mathrm{~s}$, a second stage characterised by a slower resistance increase due to the following superficial deposition (called "thickening stage") is observed. Both stages represent the reversible resistance $\left(R_{\text {rev }}\right)$ and they are related to the cake deposition on the membrane surface.

In practice, however, the initial resistance value increases slightly after each backwash because irreversible fouling occurs. This irreversible contribution to membrane fouling is caused by pore blocking that occurs in the very first seconds of the suction phase before superficial deposition and, slightly, by pore blocking and cake deposition during the entire cycle. Nevertheless, the increase of $R_{\mathrm{irr}}$ is not perceptible between two consecutive filtration cycles, because its variation is too low. That is why, in this study, the irreversible fouling was quantified only by comparing the TMP* of two cycles $24 \mathrm{~h}$ delayed.

Referring to the second classification of specific resistances, in order to evaluate $R_{\mathrm{PB}}$ and $R_{\mathrm{C}}$, it is first necessary to verify the existence of an irreversible component of $R_{\mathrm{C}}$. If the irreversible component for cake deposition is negligible, then $R_{\mathrm{PB}}$ and $R_{\mathrm{C}}$ are equal to $R_{\mathrm{irr}}$ and $R_{\mathrm{rev}}$ respectively. In order to verify and calculate $R_{\text {Cirr, }}$, a thorough nonstandard physical cleaning was performed by rinsing the membrane module with a high flow of tap water and physically washing each fibre, in accordance with reports in the literature [27,33]. Thus, on day 52 of both start-up phases a mechanical cleaning was carried out as described above. The choice of the day for physical cleaning was based on a great variation of influent quality on the previous day (see Materials and methods) and to reaching a TMP of 0.3 in the phase 1 bar. In phase 2 , the physical cleaning was done on the same day for a correct comparison of irreversible cake evolution.

As a consequence of cleaning, the membrane permeability increased (and consequently the total resistance decreased) in both phases because an irreversible fouling component was manually removed from the membrane surface. This fouling was due to the cake that was accumulating irreversibly between the membrane fibres, starting on the first day of use, and that was not removed by the recurring backwashes. Therefore this contribution was entirely attributed to $R_{\text {Cirr }}$ because the irreversible component due to the pore blocking would have been removed only by chemical cleaning $[29,42]$. The $R_{\text {Cirr }}$ component was only determined on day 52 of both start-up phases, and all the previous values were evaluated with a linear function, by fixing $R_{\text {Cirr }}=0$ on the first day of each start-up

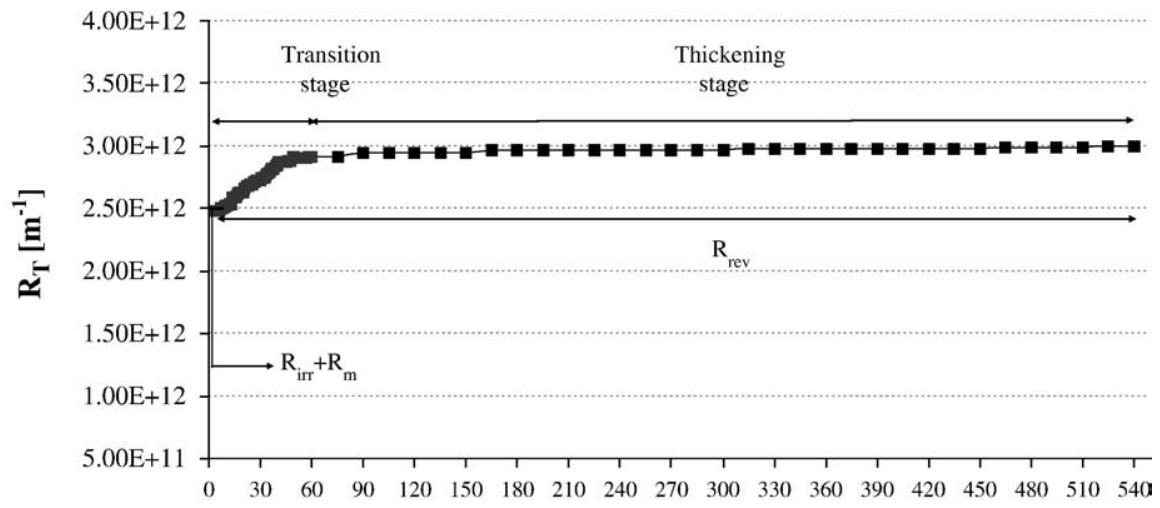

Time [s]

Fig. 6. Example of filtration cycle for the resistances investigation. 
phase. In conclusion the $R_{\mathrm{PB}}$ and $R_{\mathrm{C}}$ components can be calculated through the resistances $R_{\mathrm{irr}}$ and $R_{\mathrm{rev}}$ with the following equations:

$R_{\mathrm{PB}}=R_{\mathrm{irr}}-R_{\mathrm{Cirr}}=\left(R_{\mathrm{T}}-R_{\mathrm{m}}-R_{\mathrm{rev}}\right)-R_{\mathrm{Cirr}}$

$R_{\mathrm{C}}=R_{\mathrm{rev}}+R_{\mathrm{Cirr}}=\left(R_{\mathrm{T}}-R_{\mathrm{m}}-R_{\mathrm{irr}}\right)+R_{\mathrm{Cirr}}$.

\subsection{The role of specific fouling mechanisms}

The suction cycles, which were recorded every 5 days (before the physical cleaning) during both phases, are shown in Fig. 7.

The resistances versus time curves were much different between the two start-up phases. In particular, during the first 10 days of the start-up without inoculums, neither the transition stage nor the thickening stage occurred (Fig. 7a). These differences between the typical curves in Fig. 6 may be attributed to changes in sludge characteristics. In principle, the TSS concentration in the reactor was very low at the beginning of phase 1 , so that the cake layer on the membrane surface was negligible. On the contrary, due to the high TSS concentration, a thick cake layer was depositing on the fibres from the first day of phase 2 . This superficial deposition is shown in Fig. 7b, where the trend of each curve is very similar to the one shown in Fig. 6. In particular, during phase 1, the "height" of each curve gradually increased with increasing TSS from 0.3 to $\sim 16-17 \mathrm{~g} \mathrm{~L}^{-1}$ on day 50 (Fig. 3a). On the contrary, during phase 2 , the shape and the "height" of the transition stage remained constant because the TSS concentration in the tank was nearly constant (Fig. 3b). The interdistances between two consecutive curves are also different in both startups; in phase 1, the curve jumps were more evident during the first 15 days, while in phase 2 , the inter-distances were similar for each curve. This circumstance is explained by the intense, irreversible fouling that occurred in the first days of the start-up without inoculum; many particles, colloids and micro-molecules entered and blocked the pores because there was not any cake deposition yet acting as a pre-filter [43].

In Fig. 8, the variation trends of $R_{\mathrm{irr}}-R_{\text {rev }}$ and $R_{\mathrm{C}}-R_{\mathrm{PB}}$ resistances are shown for both start-ups and were determined as described above. The figure shows that the $R_{\text {irr }}$ trend in both start-ups never decreased, except on the 52nd day when the non-standard mechanical cleaning was performed. Because no chemical action occurred during this cleaning, only the irreversible portion of the cake was removed, but the foulants inside the pores were not. On the other hand, the $R_{\mathrm{PB}}$ and $R_{\mathrm{C}}$ trends show that the fouling decrease due to the cleaning
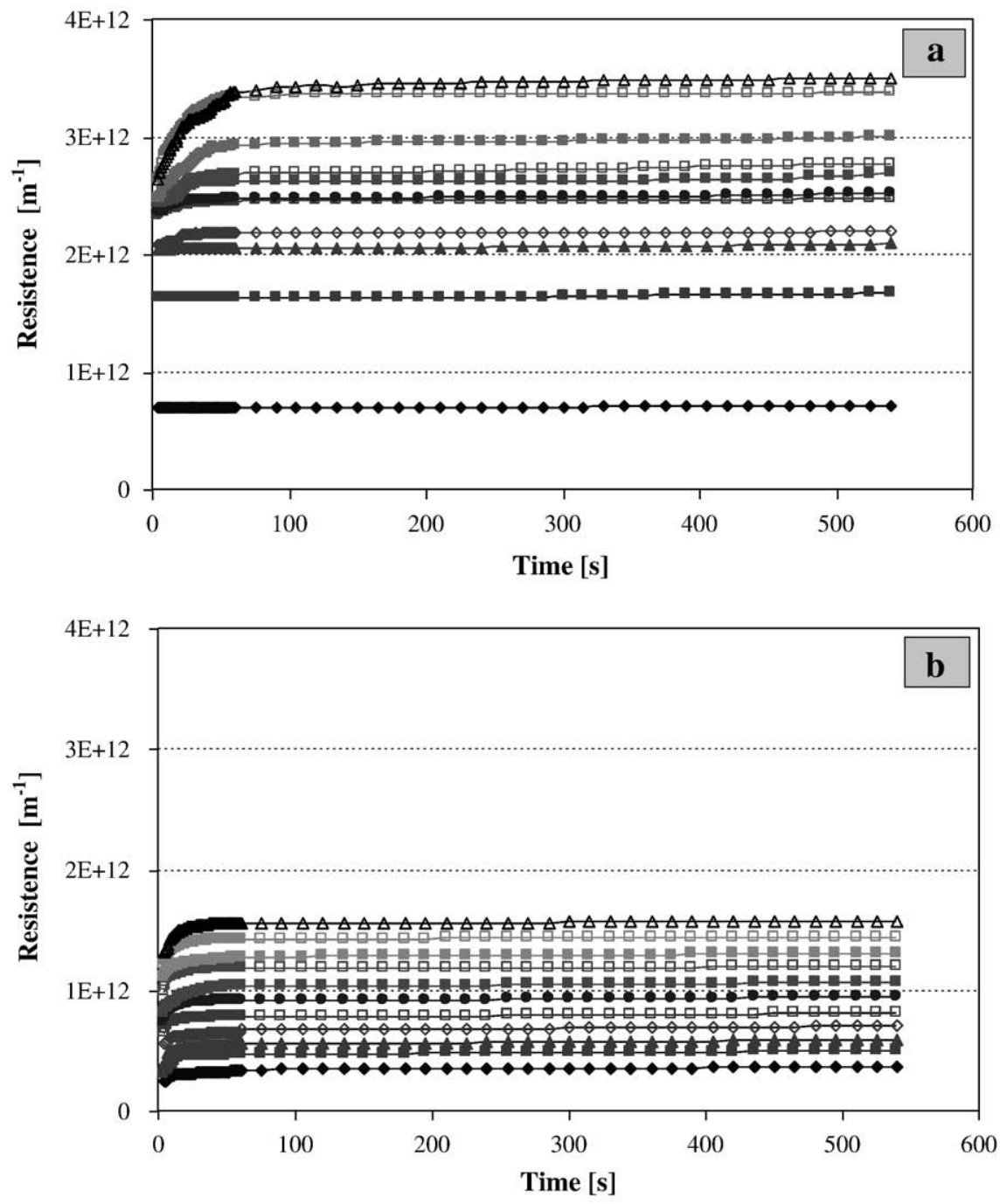

$$
\begin{aligned}
& \rightarrow \text { Day } 1 \rightarrow \text { Day } 5 \rightarrow \text { Day } 10 \rightarrow \text { Day } 15 \rightarrow \text { Day } 20 \rightarrow \text { Day } 25 \\
& \rightarrow \text { Day } 30 \rightarrow \text { Day } 35 \rightarrow \text { Day } 40 \rightarrow \text { Day } 46 \rightarrow \text { Day } 50
\end{aligned}
$$

Fig. 7. Total resistance variations during the suction cycles of start-up without (a) and with (b) inoculums. 
procedure on day 52 is entirely attributable to the removal of the irreversible foulant cake. Consequently, no $R_{\mathrm{PB}}$ decrease is visible. Nevertheless, the differences between $R_{i r r} / R_{\mathrm{PB}}$ and $R_{\mathrm{rev}} / R_{\mathrm{C}}$ for each specific start-up were very small and related to small increases in the $R_{\text {Ccirr }}$ contribution during plant function.

In general, in the start-up with inoculums, the $R_{\mathrm{irr}}$ and $R_{\mathrm{PB}}$ increased linearly, and the resistance values were always lower than those of the start-up without inoculum. In other words, the irreversible fouling increased more rapidly in the start-up without inoculum. However, the fouling due to the deposition of suspended solids on the membrane (i.e., $R_{\mathrm{rev}}$ and $R_{\mathrm{C}}$ ) was influenced by the MLSS concentration in the reactor.

In the following section, the role of soluble and suspended particles in the fouling evolution is discussed relating only $R_{\mathrm{PB}}$ and $R_{\mathrm{C}}$, though the conclusion can be extended to $R_{\mathrm{rev}}$ and $R_{\mathrm{irr}}$.

3.6. The role of soluble compounds, suspended solids and floc size on the membrane fouling

Many reports in the technical literature focus on the conflict between some experimental results, mainly related to the role of sludge concentration on membrane fouling [44-47]. However, in this work, the quick change in SS concentration (phase 1) and the quick deflocculation (mainly in phase 2) contributed to increase the importance of suspended matter on total fouling, despite the fact that the role of soluble compounds could not be neglected. 43]:

- a direct influence on the superficial deposition and consequently on the cake deposition resistances;

PHASE 1
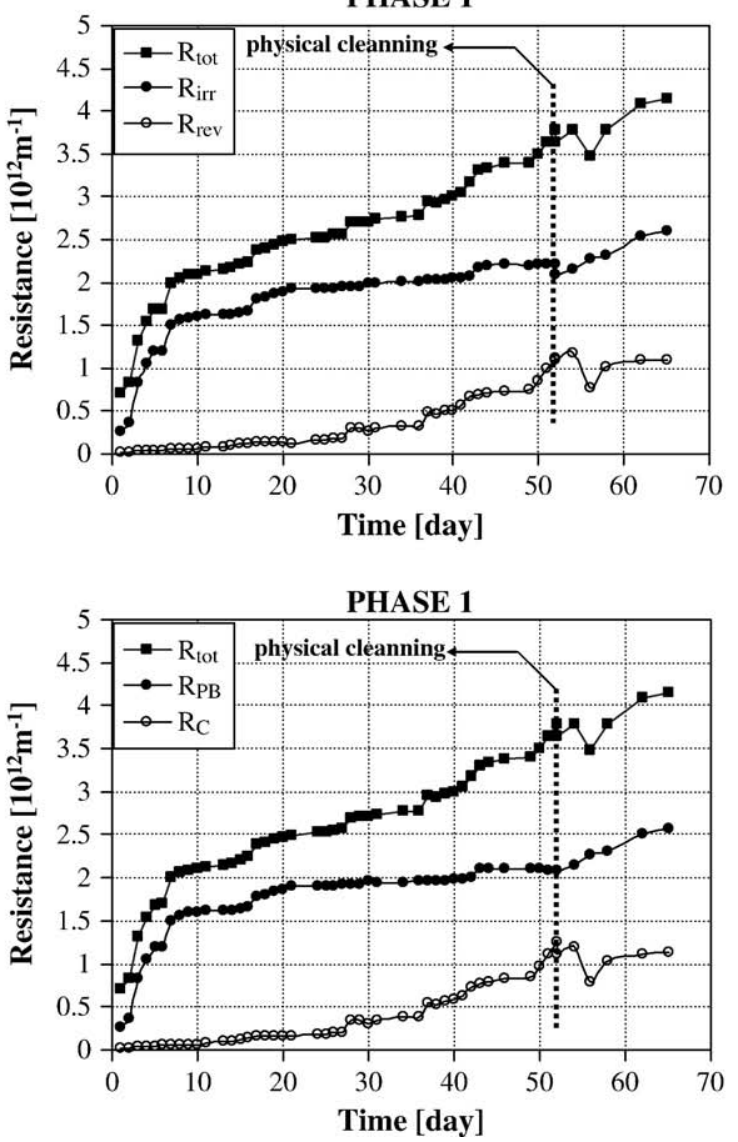

- an indirect effect due to a different pre-filter action (in phases 1 and 2) that influences the irreversible fouling due to the pore blocking mechanism.

In particular, the start-up in both phases was mainly influenced by a different cake deposition mechanism (with different cake layer formation as consequence). Furthermore, the evolution of the MLSS concentration in the reactor was different in the two start-up phases because an initial inoculum was only used in phase 2 . Consequently, as shown in the comparison of $R_{\mathrm{T}}$ and TMP evolution in both phases (before the physical cleaning) in Fig. 9 ( $a$ and b), the difference in terms of total resistances is evident (especially during the first 10 days of the two start-ups) due to irreversible deposition that is mainly influenced by the different effect of the cake layer. This is also confirmed by the Fouling Rate values (FR, $\mathrm{m}^{-1} \mathrm{~d}^{-1}$ ) in Fig. 9c.

Nevertheless, the membrane fouling was not only related to the sludge quantity but also to other parameters in MBR. In order to investigate the role of the main factors on the fouling evolution in more detail, three parameters were analysed:

- $C O D_{\text {sol-sur: }}$ the fraction of soluble COD measured in the supernatant of mixed liquor sample obtained after centrifugation at $5000 \mathrm{rpm}$ for $10 \mathrm{~min}$ and filtered through a $0.45 \mu \mathrm{m}$ filter paper (essentially, the same procedure proposed for Soluble Microbial Products or SMP separation from mixed liquor);

- MLSS: the normal SS concentration in the reactor;

- Floc size in terms of $d_{\mathrm{m}}$ : useful to characterize the cake layer.

Unfortunately, EPS and SMP were not assessed during our experiments. However, even if the types and concentrations of EPS and SMP were different during the two phases, in the first 10 days of start-up without inoculums, the influence of polymeric substances
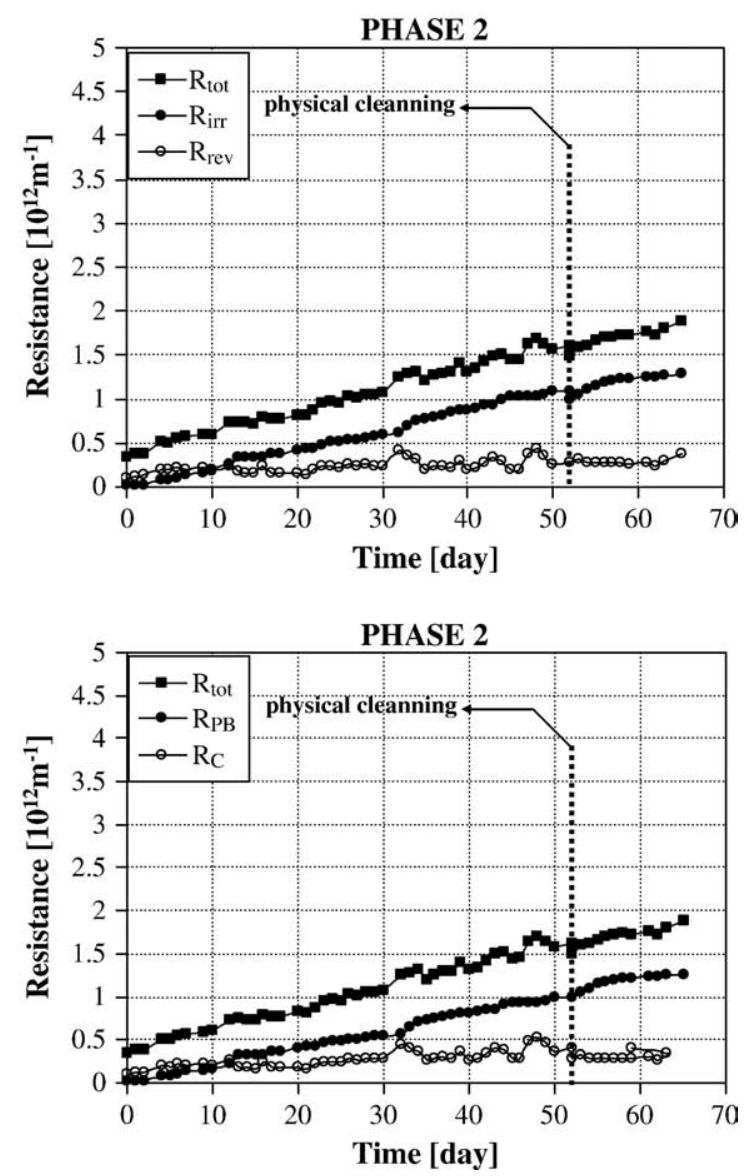

Fig. 8. $R_{\mathrm{t}}, R_{\mathrm{rev}} / R_{\mathrm{irr}}$ and $R_{\mathrm{C}} / R_{\mathrm{PB}}$ increase during start-up without (a) and with (b) inoculums. 

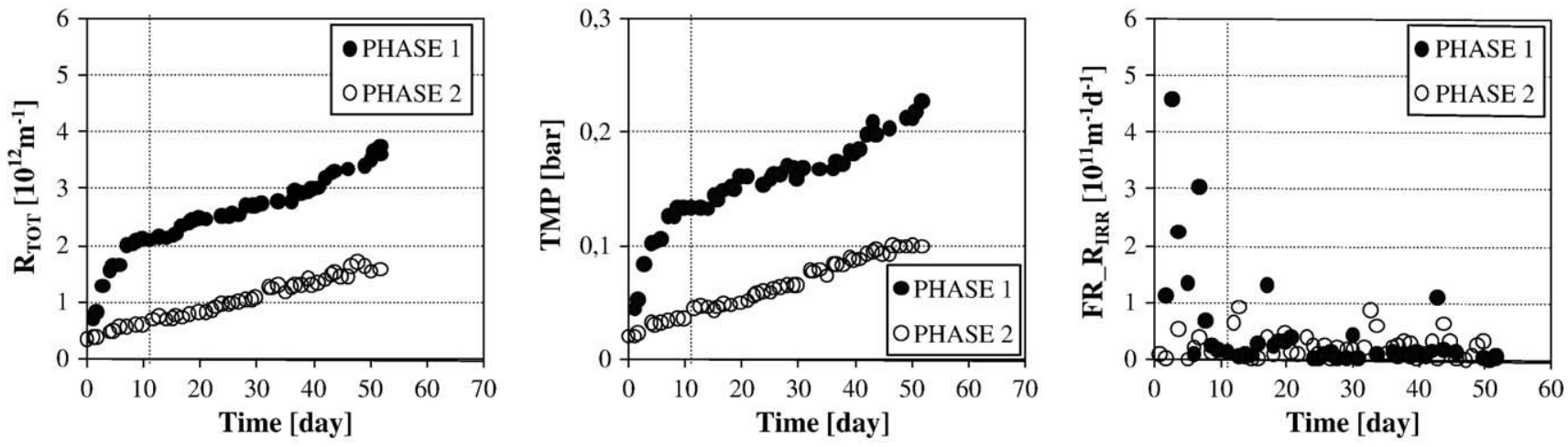

Fig. 9. Comparison of $R_{\mathrm{t}}$, TMP and specific fouling rate evolution in both phases.

produced by biomass was smaller than the total dissolved and colloidal matter in the influent. More specifically, in the first days of phase 1, the biomass concentration was negligible, and consequently, the EPS and SMP production was also negligible. On the contrary, in the second phase, the extracellular polymeric production was likely greater than in phase 1 , but this phenomenon is a disadvantage for irreversible fouling during start-up with inoculums. Despite this fact, the irreversible fouling of phase 1 was greater than the irreversible fouling in phase 2 .

The fouling increase was analysed by examining $R_{\mathrm{T}}, R_{\mathrm{PB}}, R_{\mathrm{C}}$ and specific cake resistance $(\alpha)$. In particular, the variation of the cake specific resistance $\alpha$ was calculated using the following expression [48]:

$\alpha=R_{\mathrm{rev}} \frac{A_{\mathrm{m}}}{T S S \cdot V_{\text {perm }}}$

where $A_{\mathrm{m}}$ is the membrane surface, $V_{\text {perm }}$ is the permeate volume produced during a filtration cycle, and TSS is the total suspended solid concentration. In Fig. 10 the main correlation are shown.

In general, no evident correlation between fouling increase and $\mathrm{COD}_{\text {sol-sur }}$ concentration was found, except during the first days of the start-up without inoculum (phase 1). In fact, when the biomass concentration in the reactor was low, a constant increase of irreversible fouling $\left(R_{\mathrm{PB}}\right)$ occurred. Specifically, the total absence of the cake layer caused a negligible pre-filter action and consequently there was a direct impact of influent soluble matter on membrane surface $[3,48]$. On the other hand, after the 10th day, no effects of soluble matter on the membrane irreversible fouling were clearly observed. In particular, the contemporaneous variation of all parameters (soluble and suspended matter concentration, floc size, etc) contributed to mask the single effect of soluble compounds. In this context, it would be necessary to compare the resistance increase with the actual soluble concentration that reaches the membrane surface after cake layer filtration (according to the deep bed theory reported by Kuberkar and Davis [49]). Unfortunately, it was not possible to directly evaluate the COD concentration in the cake layer/membrane interface during normal plant operation. However, as shown in Fig. 10, the increase in $R_{\mathrm{PB}}$ decreases after 10 days of operation in phase 1 . Similarly, for the entire length of the phase 2 experiment, the FR values were low and quite constant $\left(\mathrm{FR}<0.5 \cdot 10^{11} \mathrm{~m}^{-1} \mathrm{day}^{-1}\right)$. As discussed above, this circumstance was likely caused by the cake layer filtration that occurs only with a relevant MLSS concentration in the reactor, even if it was not possible to determine a specific correlation.

High MLSS variation influenced the total resistances for the entire length of phase 1 , mainly in terms of superficial deposition $\left(R_{\mathrm{C}}\right)$. In fact, the analysis of correlation reported in Fig. 10 underscores that the
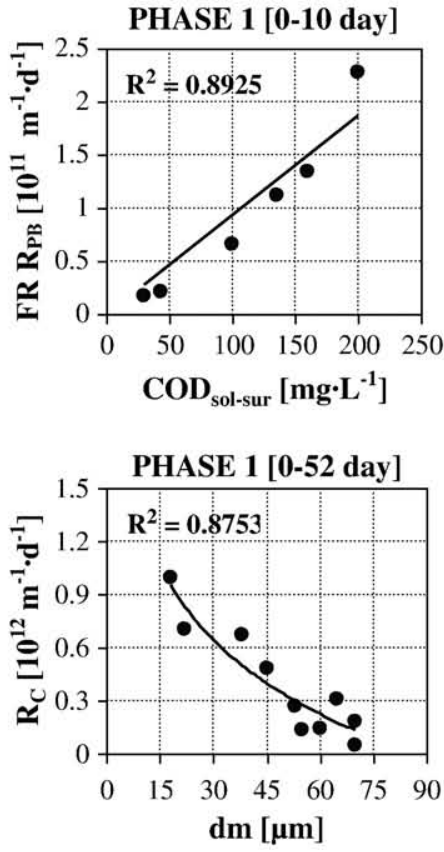

PHASE 1 [11-52 day]
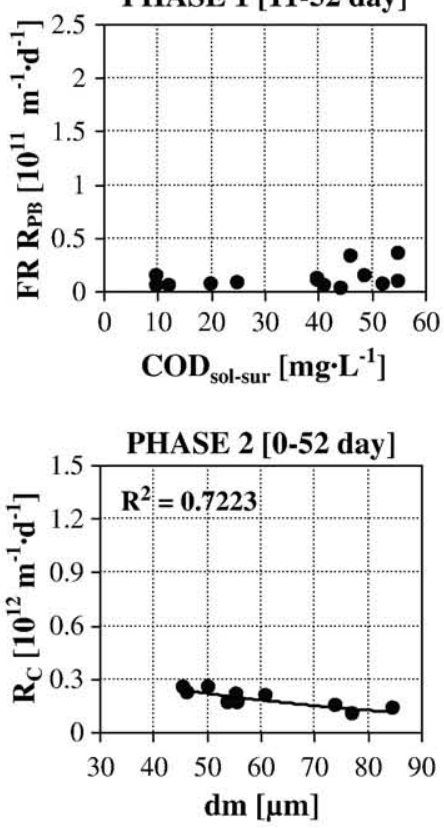
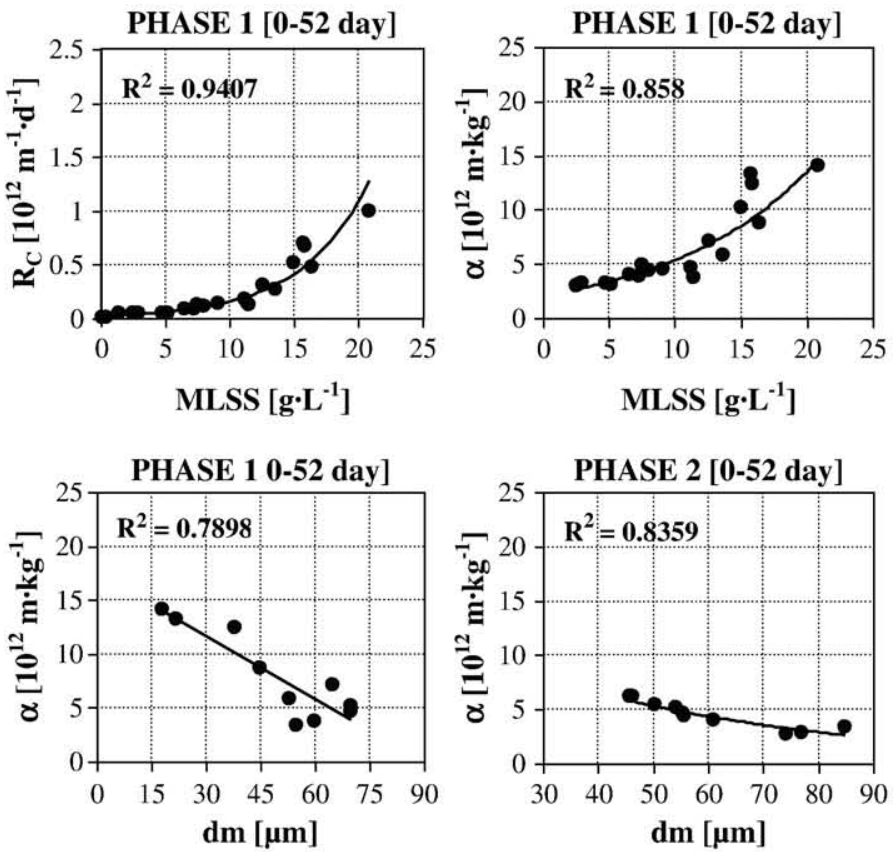

Fig. 10. Significant correlation between operational and fouling parameters. 
resistance variations were mainly correlated to cake deposition. In particular, the results show that there is an exponential relationship between MLSS concentration and cake resistance, as seen by Meng et al. [47]. Furthermore, according to Eq. (11), during the start-up without inoculum the continuous SS concentration variation also influenced the typical variation of cake layer features. Consequently, $\alpha$ can also be correlated to MLSS concentration. Unfortunately, the correlation was evident only in phase 1 , when the difference in TSS concentration, from the 1 st to the 65th days was very high. In fact, during the start-up with inoculum, when the SS concentration was kept essentially constant, a relation between MLSS and resistance fouling was not found; the $R_{\mathrm{TOT}}$ and $R_{\mathrm{C}}$ trends showed only small and homogeneous values. Obviously, the specific cake layer resistance was also influenced by the deflocculation phenomenon (Fig. 10), and it was also evident in phase 2 . In general, the superficial deposition phenomenon was influenced by floc size decreases in the two startups. In fact, the cake layer deposited onto the membrane displayed a reduction in permeability. Consequently $\alpha, R_{\mathrm{TOT}}$ and $R_{\mathrm{C}}$ tend to increase when the average flocs dimension decreases. The same result was found by other authors $[47,50]$ and was not correlated with inoculum deflocculation.

\section{Conclusion}

The paper analysed MBR start-ups, focusing on the role of the initial inoculum of activated sludge.

In particular, the experiments aimed to study the difference between a start-up with or without inoculum. The results confirm that the MBRs can be quickly and easily started-up, in both initial operating conditions. More specifically, the MBR was able to guarantee excellent organic removal performance in both start-ups. In fact, the inoculum allowed only a slight improvement of depuration performance due to the presence of a microbial population on the first day of operation. In both start-ups, complete nitrification was observed after only a few days, and the legal limits for COD removal were met from the very beginning. Regarding floc dimensions, in steady-state conditions the morphology of MBR activated sludge is characterized by flocs of $\sim 20-40 \mu \mathrm{m}$, i.e., much smaller than those usually observed in CAS systems. Due to the complete retention provided by the membrane, such small dimensions of the bacterial aggregates did not affect the effluent quality, because the permeate was always free of suspended solids. Nevertheless, such small dimensions affected the cake permeability.

Finally, unlike the removal performance results, the filtration efficiency and the membrane fouling were greatly influenced by the inoculum. In particular, the cake layer acted as a pre-filter for all dissolved and colloidal components not biodegraded by microorganisms. As a consequence this pre-filter reduces the foulant amount reaching the membrane. In this context, it is important to define more efficient conditions taking into consideration all potential foulants and a logical balance in the different fouling mechanisms: soluble compounds for irreversible fouling, sludge concentration and particle size evolution for reversible fouling.

These results can be obtained by optimization of MBR management from start-up, exploiting the pre-filter action of a cake layer and the high biological removal guaranteed from the first days of operation by an inoculum.

\section{References}

[1] P. Huang, S. Qin, Q. Zhao, X. Guo, Quick start-up of mudanjiang wastewater treatment plant and factors influencing phosphorous removal, Global Nest J. 8 (2006) $1-8$.

[2] M. Ferraris, C. Innella, A. Spagni, Start-up of a pilot-scale membrane bioreactor to treat municipal wastewater, Desalination 37 (2009) 190-200.

[3] S. Judd, The MBR book, Principles and Applications of Membrane Bioreactors in water and wastewaters treatment, Elsevier, 2006.
4] M. Ferraris, C. Innella, G. Laera, A. Spagni, Studio della fase di avviamento di bioreattori a membrana per il trattamento delle acque reflue, Ing. Ambient. XXXII (2003) 214-221.

[5] A. Pollice, G. Laera, M. Blonda, Biomass growth and activity in a membrane bioreactor with complete sludge retention, Water Res. 38 (2004) 1799-1808.

[6] G. Laera, A. Pollice, D. Saturno, C. Giordano, A. Lopez, Zero net growth in a membrane bioreactor with complete sludge retention, Water Res. 39 (2005) 5241-5249.

[7] H. Monclús, J. Sipma, G. Ferrero, J. Comas, I. Rodriguez-Roda, Optimization of biological nutrient removal in a pilot plant UCT-MBR treating municipal wastewater during start-up, Desalination 250 (2) (2010) 592-597.

8] T. Wang, H. Zhang, F. Yang, S. Liu, Z. Fu, H. Chen, Start-up of the Anammox process from the conventional activated sludge in a membrane bioreactor, Bioresour. Technol. 100 (2009) 2501-2506.

[9] Y. Xue, F. Yang, S. Liu, Z. Fu, The influence of controlling factors on the start-up and operation for partial nitrification in membrane bioreactor, Bioresour. Technol. 100 (2009) 1055-1060.

[10] W. Schier, F.B. Frechen, S. Fischer, Efficiency of mechanical pre-treatment on European MBR plants, Desalination 236 (2009) 85-93.

[11] C. Psoch, S. Schiewer, Long-term flux improvement by air sparging and backflushing for a membrane bioreactor and modelling permeability decline, Desalination 230 (2008) 193-204.

[12] APHA, Standard Methods for Examination of Water and Wastewater, American Public Health Association/American Water Works Association/Water Environment Federation, Washington, DC, USA, 1995.

[13] F. Durante, G. Di Bella, M. Torregrossa, G. Viviani, Particle size distribution and biomass growth in a submerged membrane bioreactor, Desalination 200 (2006) 493-495.

[14] T.A. Mohammed, A.H. Birima, M.J. Noor, S.A. Muyibi, A. Idris, Evaluation of using membrane bioreactor for treating municipal wastewater at different operating conditions, Desalination 221 (2008) 502-510.

[15] W. Khongnakorn, C. Wisniewski, L. Pottier, L. Vachoud, Physical properties of activated sludge in a submerged membrane bioreactor and relation with membrane fouling, Sep. Pur. Technol. 55 (2007) 125-131.

[16] T. Stephenson, S. Judd, B. Jefferson, K. Brindle, Membrane Bioreactors for Wastewater Treatment, IWA, 2000.

[17] Metcalf, Eddy, Ingegneria delle acque reflue - Trattamento e riuso, Edition IVMcGraw-Hill, New York, 2006.

[18] T. Wintgens, J. Rosen, T. Melin, C. Brepols, K. Drensla, N. Engelhardt, Modelling of a membrane bioreactor system for municipal wastewater treatment, J. Membr. Sci. 138 (2003) 403-411.

[19] X. Huang, P. Gui, Y. Qian, Effect of sludge retention time on microbial behaviour in a submerged membrane bioreactor, Process Biochem. 36 (2001) 1001-1006.

[20] H.Y. Ng, S.W. Hermanowicz, Membrane bioreactor operation at short solids retention times: performance and biomass characteristics, Water Res. 39 (2005) 981-992.

[21] C.A. Biggs, P.A. Lant, Activated sludge flocculation: on-line determination of floc size and the effect of shear, Water Res. 34 (9) (2000) 2542-2550.

[22] M. Spérandio, A. Massé, M.C. Espinosa-Bouchot, C. Cabassud, Characterization of sludge structure and activity in submerged membrane bioreactor, Water Sci. Technol. 52 (2005) 401-408.

[23] L. Ji, J. Zhou, Influence of aeration on microbial polymers and membrane fouling in submerged membrane bioreactors, J. Membr. Sci. 276 (2006) 168-177.

[24] J. Lobos, C. Wisniewski, M. Heran, A. Grasmick, Sequencing versus continuous membrane bioreactors: effect of substrate to biomass ratio $(F / M)$ on process performance, J. Membr. Sci. 317 (2008) 71-77.

[25] S. Smith, S. Judd, T. Stephenson, B. Jefferson, Membrane bioreactors - hybrid activated sludge or a new process? CHISA, Prague, 2002

[26] R.P. Merlo, R.S. Trussell, S.W. Hermanowicz, D. Jenkins, Phisical, chemical and biological properties of submerged membrane bioreactors and conventional activated sludges, Proceedings of the Congress: WEFTEC 2004 - The water quality event. New Orleans, LA USA, October 3-6, 2004

[27] F.G. Meng, H.M. Zhang, Y.S. Li, X.W. Zhang, F.L. Yang, J.N. Xiao, Cake layer morphology in microfiltration of activated sludge wastewater based on fractal analysis, Sep. Purif. Technol. 44 (2005) 250-257.

[28] E. Reid, X. Liu, S. Judd, Effect of high salinity on activated sludge characteristics and membrane permeability in an immersed membrane bioreactor, J. Membr. Sci. 283 (2006) 164-171.

[29] H. Choi, K. Zhang, D.D. Dionysiou, D.B. Oerther, G.A. Sorial, Effect of permeate flux and tangential flow on membrane fouling for wastewater treatment, Sep. Purif. Technol. 45 (2005) 68-78.

[30] B.K. Hwang, W.N. Lee, P.K. Park, C.H. Lee, I.S. Chang, Effect of membrane fouling reducer on cake structure and membrane permeability in membrane bioreactor, J. Membr. Sci. 288 (2007) 149-156.

[31] J. Busch, A. Cruse, W. Marquardt, Modeling submerged hollow-fiber membrane filtration for wastewater treatment, J. Membr. Sci. 288 (2007) 94-111.

[32] S.J. Duranceau, Membrane practices for water treatment, 1st edAmerican Water Works Association, Denver, $2001 \mathrm{CO}$

[33] Chu HP, Li XY. Membrane fouling in a membrane bioreactor (MBR): sludge cake formation and fouling characteristics. Published online 30 March 2005 in Wiley InterScience (www.interscience.wiley.com)

[34] K. Kimura, T. Miyoshi, T. Naruse, N. Yamato, R. Ogyu, Y. Watanabe, The difference in characteristics of foulants in submerged MBRs caused by the difference in the membrane flux, Desalination 231 (2008) 268-275.

[35] A. Broeckmann, T. Wintgens, A.I. Schätfer, Removal and fouling mechanisms in nanofiltration of polysaccharide solutions, Desalination 178 (2005) 149-159. 
[36] M.T. Pessoa de Amorim, I.R. Ramos, Control of irreversible fouling by application of dynamic membrane, Desalination 192 (2006) 63-67.

[37] K. Kimura, T. Naruse, Y. Watanabe, Changes in characteristics of soluble microbial products in membrane bioreactors associated with different solid retention times: relation to membrane fouling, Water Res. 43 (2009) 1033-1039.

[38] K. Katsoufidou, S.G. Yiantsios, A.J. Karabelas, A study of ultrafiltration membrane fouling by humic acids and flux recovery by backwashing; experiments and modelling, J. Membr. Sci. 266 (2005) 40-50.

[39] T. Jiang, M.D. Kennedy, W.G.J. van der Meer, P.A. Vanrolleghem, J.C. Schippers, The role of blocking and cake filtration in MBR fouling, Desalination 157 (2003) 335-343.

[40] Y. Ye, P. Le Clech, V. Chen, A.G. Fane, Evolution of fouling during crossflow filtration of model EPS solutions, J. Membr. Sci. 264 (2005) 190-199.

[41] G. Di Bella, F. Durante, M. Torregrossa, G. Viviani, P. Mercurio, A. Cicala, The role of fouling mechanisms in a membrane bioreactor, Water Sci. Technol. 55 (8-9) (2007) 455-464.

[42] H.Y. Ng, A.S. Kim, A mini-review of modelling studies on membrane bioreactor (MBR) treatment for municipal wastewater, Desalination 212 (2007) 261-281.
[43] G. Di Bella, G. Mannina, G. Viviani, An integrated model for physical-biological wastewater organic removal in a submerged membrane bioreactor: Model development and parameter estimation, J. Membr. Sci. 322 (2008) 1-12.

[44] S. Rosemberger, M. Kraume, Filterability of activated sludge in membrane bioreactors, Desalination 143 (2003) 373-379.

[45] S. Arabi, G. Nakhla, Impact of protein/carbohydrate in feed wastewater on the membrane fouling in membrane bioreactor, J. Membr. Sci. 324 (2008) 142-150.

[46] L. Defrance, M.Y. Jaffrin, Reversibility of fouling formed in activated sludge filtration, J. Membr. Sci. 157 (1999) 73-84.

[47] F.G. Meng, H.M. Zhang, F.L. Yang, X.W. Zhang, Y.S. Li, Identification of activated sludge properties affecting membrane fouling in submerged membrane bioreactor, Sep. Purif. Technol. 51 (2006) 95-103.

[48] C. Psoch, S. Schiewer, Critical flux aspect of air sparging and backflushing on membrane bioreactors, Desalination 175 (2006) 284-297.

[49] V.T. Kuberkar, R. Davis, Modeling of fouling reduction by secondary membranes, J. Membr. Sci. 168 (2000) 243-257.

[50] C. Wisniewski, A. Grasmick, Floc size distribution in a membrane bioreactor and consequences for membrane fouling, Colloids Surf. 138 (1998) 403-411. 